\title{
Optimal planning of a biofuel supply chain using a multi-criteria optimisation model
}

\author{
S. Syafiie*
}

Department of Chemical and Environmental Engineering, University Putra Malaysia, Serdang Selangor DE, Malaysia and Department of Chemical Engineering, Syiah Kuala University, Banda Aceh, Indonesia

Email: s.syafiie@gmail.com

*Corresponding author

\section{Maryam Valizadeh}

Department of Chemical and Environmental Engineering, University Putra Malaysia,

Serdang Selangor DE, Malaysia

Email: maryam_valizadeh65@yahoo.com

\begin{abstract}
Biofuels, for reasons such as the high demand of fossil fuels, the need for energy security and concerns over greenhouse gas emissions, have attracted the attention of researchers. Production of biofuels can be costly. On the other hand, the environmental benefits of biofuels depend on the technique they are produced, transported and used. This article studies a mathematical programming model for optimal planning of a biofuel supply chain based on existing facilities. The developed model is based on multi-objective linear programming (MOLP) and considers the economic, environmental and social concerns related to the proposed biofuel supply chain. The model takes into account feedstock availability, biofuel demand, existing biofuel plants and processing technologies. The proposed model is used to evaluate biodiesel production from palm oil and jatropha oil based on existing biodiesel plants in Malaysia. From developed model, the $\varepsilon$-constraint method is applied to solve the optimisation problem. Solving of the proposed model determines the optimal quantity of biomass to be harvested, transportation schedules and the quantity of biodiesel produced at biorefineries as well.
\end{abstract}

Keywords: biofuel; optimisation; linear programming; biodiesel; palm oil; jatropha; social factor.

Reference to this paper should be made as follows: Syafiie, S. and Valizadeh, M. (2016) 'Optimal planning of a biofuel supply chain using a multi-criteria optimisation model', Int. J. Process Systems Engineering, Vol. 4, No. 1, pp.1-18. 
Biographical notes: S. Syafiie received his Bachelor in Chemical Engineering from Syiah Kuala University, Indonesia in 1998. He continue studied in systems engineering and automatic control in University of Valladolid, Spain. He received his Master and $\mathrm{PhD}$ from the university in 2004 and 2007, respectively. He is currently a Lecturer at University Putra Malaysia.

Maryam Valizadeh received her Bachelor in Chemical Engineering - Food Processing from Azad University Dezful, Iran in 2009. She received her Master from Department of Chemical and Environmental Engineering, University Putra Malaysia in 2014.

\section{Introduction}

Recently, issues such as energy demand growth, energy consumption, and emissions, have increased attention of researchers given to natural energy resources. It has been predicted that the world's demand for energy will increase by $50 \%$ to $60 \%$ by 2030 (Holditch and Chianelli, 2008), as a result of population growth and the pursuit of higher living standards. Biomass has been considered as a good substitute to encounter this increased demand due to the fluctuation price of petroleum and the future uncertainty of its availability (Santibanez-Aguilar et al., 2011; National Petroleum Council, 2007; Rosegrant et al., 2006). To satisfy future energy demands, renewable energy derived from wind, biomass, and solar resources has great growth potential (Drapcho et al., 2008; Ong et al., 2011). Biofuel energy is considered a type of renewable energy produced from biomass resources.

Although biofuels have the potential to be used as alternatives for future fuel demand, their large scale production costs are high when compared to fossil fuels (Zarrilli, 2006). Another issue is the management of crops used for the production of some types of biofuel and the amount of land needed for cultivation of these crops. It can also be a source of agro-residues for biofuel production. The growing demand for biomass sources, which are also cultivated for food, such as palm oil, corn and soybean, to produce biofuel has been one of the factors of increased food prices (FAO, 2008; Popp et al., 2014). Increased demand for these crops may lead to deforestation due to the area required for cultivation of energy crops, which will result in greenhouse gas (GHG) emissions. The climate change mitigation potential of biofuels depends on other factors, such as the biomass cultivation process adopted, as well as the processing technologies used for the production of biofuels from biomass (FAO, 2008; Timilsina and Shrestha, 2011).

An effective strategy is needed for production of sustainable biofuel. In this paper, an optimisation model considering financial, environmental as well as social criteria of the biofuel supply chain is introduced. The model is multi-objective and aims to maximise the economic performance of the biofuel industry by minimising the total operational costs associated to biofuel production stages and minimises the environmental and social impacts by reducing, as much as possible, GHG emissions and the quantity of edible feedstocks consumed for biofuel production, respectively.

In recent years, considerable attention has been devoted to biofuel production and biofuel supply chain optimisation (Kim et al., 2011). A variety of models exist that 
present the optimal design and planning of a biofuel supply chain. Several research works have focused on the development of mathematical models for improving the economic performance of biofuels by minimising total costs (Gunnarsson et al., 2004; Dunnett et al., 2007; Eksioğlu et al., 209). Parker et al. (2010) proposed a mixed integer nonlinear programming (MINLP) model to identify the most efficient configuration of a biofuel supply chain, considering annual profit as an objective. They evaluated the optimal production and distribution of biohydrogen from agricultural residues. A multistage mixed integer linear programing (MILP) model was addressed by Huang et al. (2010) for the strategic planning of a bioethanol supply chain to minimise the total system cost throughout the planning horizon. This model determines the size and location (see Marvin et al., 2013) of new refineries and also supplemental capacities and material flows of feedstock and bioethanol; however, the proposed model only took into account the economic aspect of the bioethanol supply chain.

Some researchers have used mathematical models to maximise the profit of a biofuel network (An et al., 2011; Corsano et al., 2011). An et al. (2011) proposed a mathematical model for optimisation of a lignocellulosic biofuel supply chain in order to prescribe the locations and capacities of facilities, material flows and technologies. Corsano et al. (2011) considered the optimisation of sugar-bioethanol supply chain. They used a MINLP model for optimal design and analysis of a bioethanol supply chain producing biofuel from sugar cane. Some studies have been conducted to consider the environmental performance of the biofuel supply chain in addition to its economic performance (Mele et al., 2009; Giarola et al., 2011; You and Wang, 2011), where the different to this study that it is considering the emission factors from harvesting, processing and transporting processes also the social factor such as edible or non-edible resource.

In a study by Mele et al. (2009), a multi-objective MILP model was presented which addresses the design of a sugar and ethanol supply chain while minimising the total cost of the system and environmental impacts as well. Giarola et al. (2011) have used a multi-objective MILP framework for the strategic design and planning of a bioethanol supply chain and optimisation of environmental and financial performances through the first and second generation process. The model is multi-period and provides decisions assessing the economic and environmental performances of the supply chain. A multi-objective multi-period MILP approach for design and operation of a biomass to liquid supply chain by taking into consideration the economic and environmental criteria was described in the work of You and Wang (2011). The model seeks the minimisation of the total annualised cost and GHG emissions and determines the optimal network, facility locations, process technology, capital cost, level of inventory and logistics decisions.

The modelling of a biofuel supply chain needs other considerations to become more sustainable, such as social criteria. Limited works have been conducted to investigate social issues in the optimisation of a biofuel supply chain in addition to economic and environmental criteria. The consideration of a social objective related to the development of a biofuel supply chain was presented in You et al. (2012). They proposed an approach for the optimal design and operation of a cellulosic bioethanol supply chain. They developed a multi-objective MILP model under economic, environmental and social criteria. The number of local jobs created was taken into account as the social objective and life cycle of GHG emissions were measured as the environmental objective. The model determines the optimal design and plan of the supply chain, locations of facilities, 
capital investment, inventory and logistics decisions involved in establishing a biofuel supply chain. In this study, the $\epsilon$-constrained method is applied to solve optimisation problem. The $\epsilon$-constrained method is an algorithm transformation method, which can convert algorithms for unconstrained problems to algorithms for constrained problems using the $\epsilon$ level comparison, which compares search points based on the pair of objective value and constraint violation of them (Mavrotas, 2009; Yang et al., 2014; Liu and Papageorgiou, 2013).

The food versus fuel conflict is the other important social issue in the production of biofuels. Some feedstocks used for biofuel production are also important sources of food for humans or animals and compete with food crops. Furthermore, using more crops leads to an increase of food prices. The modelling of a biofuel supply chain by taking into account this social issue leads to more sustainable biofuel production.

This study focuses on the optimal planning of a biofuel supply chain based on available resources and facilities through the development of a mathematical model. It considers the minimisation of annualised operational costs, GHG emissions in the form of $\mathrm{CO}_{2}$ equivalent and quantity of edible feedstocks consumed for production of biofuel over the entire supply chain. In this study, edible feedstock is palm oil, while non-edible feedstock is jatropha oil. The proposed mathematical approach is a multi-objective linear programming (MOLP) model and it takes into account optimal selection of feedstock, harvesting and transportation schedules, as well as biofuel production in biorefineries. Model development of MOLP for closed loop supply chain has been study by Godichaud and Amodeo (2015) and Bottani et al. (2015) and production distribution by Niknamfar (2015). However, the authors were not study the environmental and social factors.

There are several options for the optimal planning of a biofuel supply chain. In real world situations, there are some uncertainties, such as supply, demand and operational uncertainties, which could impact the performance of the supply chain. Improving the proposed model in order to consider these uncertainties could be a future extension of this research.

\section{Problem statement}

This research investigates the optimal planning of a biofuel supply chain by the development of a mathematical model considering the economic, environmental and social criteria. the economic factors are including harversting, preprocessing, transporting and processing costs. The proposed model seeks to minimise the total production cost, GHG emissions and quantity of edible feedstocks consumed for the production of biofuel. The general structure of the supply chain network considered in this study includes:

- a set of biomass resources where biomass types are cultivated and harvested

- a set of production sites where biomass is converted to biofuels

- a set of demand zones.

The objective is to determine the optimal quantity of biomass to be harvested, optimal biomass feedstock and biofuel flows and optimal quantity of biofuel to be produced 
at biorefineries so that the total operational cost, GHG emissions and edible feedstock consumption are minimised.

The model development is covering the following. Harvesting $i$ type of biomass in field of $h$ is assumed nearby location $l$ of preprocessing. Assumed that transportation costs from harvested biomass $h$ to preprocessing plant $l$ are covered by harvesting process cost, which is $C_{i, l}^{h a r}$. In other hand, during harvesting, there is emission produced, which is called $E_{i}^{p}$. Similarly, preprocessing biomass needs $\operatorname{cost} C_{i}^{p r e}$ and produces emission $E_{i}^{\text {pre }}$. After preprocessing, biomass $i$ s are transported to processing plant $w$. Transportation cost is $T 1_{i}^{r \mid s}$ and transportation emission is $E t_{i}^{r \mid s}$. Similarly for processing plant and transportation from processing plant to demand zones. This is simplified in Figure 1.

Figure 1 Biodiesel supply chain (see online version for colours)

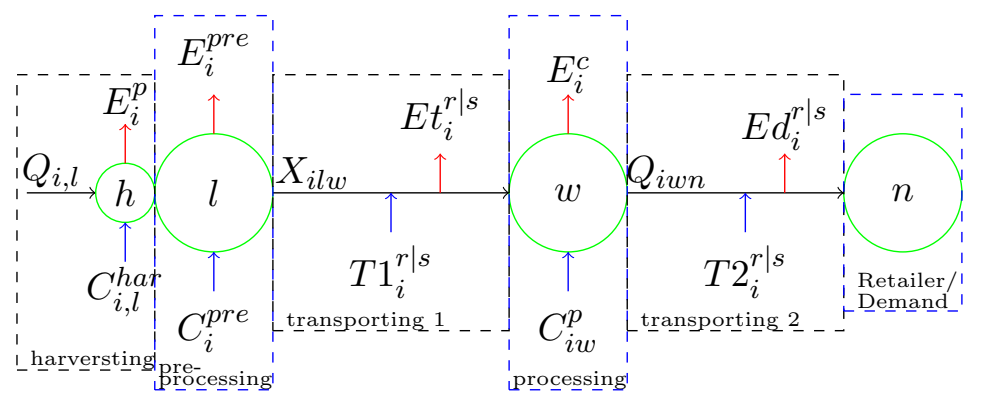

Table 1 List of indices

\begin{tabular}{ll}
\hline Indices & Description \\
\hline$i$ & Type of biomass feedstock, $i=1, \ldots, I$ \\
$l$ & Feedstock resource, $l=1, \ldots, L$ \\
$w$ & Biorefinery, $w=1, \ldots, W$ \\
$n$ & Demand zone, $n=1, \ldots, N$ \\
\hline
\end{tabular}

The indices accordingly are listed in Table 1 . The input parameters related to Figure 1 and decision variables are presented in Table 2 and Table 3, respectively.

\section{Mathematical formulation}

\subsection{Economic objective}

The economic objective to be minimised is the total operational cost of the system throughout the planning horizon. The planning horizon is set to one year. Similar model has been studied by You et al. (2012). The total operational cost $\left(C^{\text {Total }}\right)$ includes biomass production and harvesting cost $\left(C_{\text {har }}\right)$, feedstock pre-processing cost $\left(C_{\text {pre }}\right)$, feedstock transportation cost $\left(C_{t r}\right)$, biofuel production cost $\left(C_{\text {pro }}\right)$ and distribution cost $\left(C_{d s}\right)$. It should be noted that capital cost is not included in this study.

$$
C^{\text {Total }}=C_{\text {har }}+C_{\text {pre }}+C_{t r}+C_{\text {pro }}+C_{d s}
$$


Table 2 List of parameters

\begin{tabular}{ll}
\hline Parameter & Description \\
\hline$Y_{i, l}$ & Maximum availability of biomass $i$ at resource $l$ \\
$\eta_{i}$ & Conversion factor for pre-processing of feedstock type $i$ \\
$\alpha_{i}$ & Conversion factor for production of biofuel from \\
& pre-processed feedstock type $i$ \\
$R e f_{w}$ & Maximum capacity of biorefinery $w$ \\
$D_{n}$ & Demand at demand zone $n$ \\
$C_{i, l}^{\text {har }}$ & Production and harvesting cost of biomass feedstock type $i$ \\
$C_{i}^{p r e}$ & at resource $l$ \\
$T 1_{i}^{r}$ & Pre-processing cost of feedstock type $i$ \\
$T 1_{i}^{s}$ & Transportation cost of feedstock type $i$ via road \\
$D_{l, w}$ & Transportation cost of feedstock type $i$ via ocean \\
$C_{i, w}^{p}$ & Distance between resource $l$ and biorefinery $w$ \\
$T 2_{i}^{r}$ & Production cost of biofuel from feedstock type $i$ \\
$T 2_{i}^{s}$ & at biorefinery $w$ \\
$D{ }_{w}, n$ & Transportation cost of biofuel via road \\
$E_{i}^{p}$ & Transportation cost of biofuel via ocean \\
$E_{i}^{p r e}$ & Distance between biorefinery $w$ and demand zone $n$ \\
$E t_{i}^{r}$ & Emission factor for production and harvesting of biomass type $i$ \\
$E t_{i}^{s}$ & Emission factor for pre-processing of biomass type $i$ \\
$E_{i}^{c}$ & Emission factor for transportation of feedstock type $i$ via road \\
$E d_{i}^{r}$ & Emission factor for transportation of feedstock type $i$ via ocean \\
$E d_{i}^{s}$ & Emission factor for biofuel production \\
\hline & Emission factor for distribution of biofuel via road \\
& Emission factor for distribution of biofuel via ocean \\
\hline
\end{tabular}

Table 3 List of decision variables

\begin{tabular}{ll}
\hline Decision variable & Description \\
\hline$Q_{i, l}$ & $\begin{array}{l}\text { Quantity of biomass type } i \text { to be harvested } \\
\text { from resource } l\end{array}$ \\
& Quantity of pre-processed feedstock type $i$ \\
$X_{i, l, w}$ & shipped from resource $l$ to biorefinery $w$ \\
$X_{i, w}^{f}$ & Quantity of biofuel produced from feedstock type $i$ \\
$Q_{i, w, n}^{f}$ & at biorefinery $w$
\end{tabular}

The components of total operational cost are as follows:

Equation (2) represents the biomass production and harvesting cost. The production and harvesting cost of biomass equals the sum of the all biomass types harvested from all resources multiplied by their associated production and harvesting cost $\left(C_{i, l}^{h a r}\right)$.

$$
C_{h a r}=\sum_{i} \sum_{l} Q_{i, l} \cdot C_{i, l}^{h a r}
$$


Equation (3) shows the pre-processing cost of the feedstock. It is assumed that all harvested biomass are pre-processed as soon as possible after harvesting, so the pre-processing cost of the feedstock is equal to the total quantity of biomass harvested from all resources, multiplied by their relevant pre-processing cost $\left(C_{i}^{\text {pre }}\right)$.

$$
C_{\text {pre }}=\sum_{i} \sum_{l} Q_{i, l} \cdot C_{i}^{p r e}
$$

The transportation cost of the feedstock, equation (4), is equal to the sum of all pre-processed feedstock which is shipped from resources to biorefineries multiplied by distance-dependent road transportation cost $\left(T 1_{i}^{r}\right)$ and ocean freight $\left(T 1_{i}^{s}\right)$.

$$
C_{t r}=\sum_{i} \sum_{l} \sum_{w} X_{i, l, w}\left[\left(T 1_{i}^{r} \cdot D_{l, w}\right)+T 1_{i}^{s}\right]
$$

Equation (5) shows the production cost of biofuel, which equals the total amount of biofuel produced from all biomass types at all biorefineries multiplied by the corresponding production cost $\left(C_{i, w}^{p}\right)$.

$$
C_{\text {pro }}=\sum_{i} \sum_{w} X_{i, w}^{f} \cdot C_{i, w}^{p}
$$

Equation (6) describes the distribution cost of biofuel, which is equal to the total amount of biofuel shipped from biorefineries to demand zones multiplied by distance-dependent road distribution cost $\left(T 2_{i}^{r}\right)$ and ocean freight $\left(T 2_{i}^{s}\right)$.

$$
C_{d s}=\sum_{i} \sum_{w} \sum_{n} Q_{i, w, n}^{f}\left[\left(T 2_{i}^{r} \cdot D \prime_{w, n}\right)+T 2_{i}^{s}\right]
$$

\subsection{Environmental objective}

The environmental evaluation includes GHG emissions through the biofuel supply chain. The total GHG emissions resulting from the biofuel supply chain $\left(E^{\text {Total }}\right)$, equation (7), is defined as the summation of emissions from biomass production and harvesting $\left(E_{\text {har }}\right)$, emissions from pre-processing of the biomass feedstock $\left(E_{\text {pre }}\right)$, emissions from the transportation of the feedstock $\left(E_{t r}\right)$, emissions from biofuel production $\left(E_{\text {pro }}\right)$ and emissions from the distribution of biofuel $\left(E_{d s}\right)$. The environmental objective is reported in terms of $\mathrm{CO}_{2}$ emissions.

$$
E^{\text {Total }}=E_{\text {har }}+E_{\text {pre }}+E_{t r}+E_{\text {pro }}+E_{d s}
$$

The total emissions from the production and harvesting of biomass feedstock are shown in equation (8). This term equals the sum of the all biomass types harvested from all resources multiplied by their corresponding emission factor $\left(E_{i}^{p}\right)$.

$$
E_{h a r}=\sum_{i} \sum_{l} Q_{i, l} \cdot E_{i}^{p}
$$


Equation (9) represents the emissions from the pre-processing of feedstock. This equation expresses that the total emissions from pre-processing of feedstock equal the sum of the all biomass types harvested from resources multiplied by their related pre-processing conversion factor $\left(\eta_{i}\right)$ and pre-processing emission factor $\left(E_{i}^{\text {pre }}\right)$.

$$
E_{\text {pre }}=\sum_{i} \sum_{l}\left(Q_{i, l} \cdot \eta_{i}\right) E_{i}^{p r e}
$$

The total emissions from the transportation of the feedstock from resources to biorefineries are defined in equation (10).

$$
E_{t r}=\sum_{i} \sum_{l} \sum_{w} X_{i, l, w}\left(E t_{i}^{r} \cdot D_{l, w}+E t_{i}^{s} \cdot D s_{l, w}\right)
$$

where $\left(E t_{i}^{r}\right)$ and $\left(E t_{i}^{s}\right)$ are emission factors for transportation of feedstock via road and ocean, respectively.

The total emissions from the conversion of the feedstock to biofuel equal the total amount of biofuel produced at all biorefineries multiplied by corresponding production emission factor $\left(E_{i}^{c}\right)$, equation (11).

$$
E_{\text {pro }}=\sum_{i} \sum_{w} X_{i, w}^{f} \cdot E_{i}^{c}
$$

Equation (12) presents the total emissions from the distribution of biofuel from biorefineries to demand zones.

$$
E_{d s}=\sum_{i} \sum_{w} \sum_{n} Q_{i, w, n}^{f}\left(E d_{i}^{r} \cdot D \prime_{w, n}+E d_{i}^{s} \cdot D \iota s_{w, n}\right)
$$

where $\left(E d_{i}^{r}\right)$ and $\left(E d_{i}^{s}\right)$ are emission factors for distribution of biofuel via road and ocean, respectively.

\subsection{Social objective}

The social objective of this study is the minimisation of the total amount of edible feedstocks consumed for biofuel production $\left(Q_{e}^{\text {Total }}\right)$. Edible feedstocks are feedstocks which are common between human food resources and feedstocks used for the production of biofuel. Equation (13) represents the social term:

$$
Q_{e}^{\text {Total }}=\sum_{i} \sum_{l} Q_{i, l} \cdot \beta_{i}
$$

where $\beta_{i}$ equals 1 if the feedstock is edible, otherwise it equals 0 . 


\subsection{Constraints}

The constraints take into account the major characteristics of the biofuel supply chain, such as feedstock and facility availability, biorefinery capacities and biofuel demand.

Due to the fact that it is not possible to harvest feedstock above the available quantity, the total amount of biomass feedstock type $i$ that is collected from feedstock resource $l\left(Q_{i, l}\right)$, cannot exceed its maximum yield $\left(Y_{i, l}\right)$.

$$
Q_{i, l} \leq Y_{i, l} \quad \forall i \in I, l \in L
$$

It is assumed that the pre-processing facilities are located close to the fields and resources and all harvested biomass are pre-processed as soon as possible after harvesting. All the pre-processed feedstocks are shipped to biorefineries.

$$
Q_{i, l} \cdot \eta_{i}=\sum_{w} X_{i, l, w} \quad \forall i \in I, l \in L
$$

where $\eta_{i}$ is the pre-processing conversion factor for feedstock type $i$ and $X_{i, l, w}$ is the amount of feedstock type $i$ that is shipped from resource $l$ to biorefinery $w$.

The total amount of biofuel produced at each biorefinery $w$, equals the amount of transported feedstocks from all resources to each biorefinery multiplied by its conversion factor.

$$
X_{i, w}^{f}=\sum_{l} X_{i, l, w} \cdot \alpha_{i} \quad \forall i \in I, w \in W
$$

$X_{i, w}^{f}$ is the amount of biofuel produced from feedstock type $i$ at biorefinery $w$ and $\alpha_{i}$ is the conversion factor for biofuel produced from feedstock type $i$.

The total amount of biofuel produced from all types of feedstocks at biorefinery $w$, should not exceed the maximum refinery capacity.

$$
\sum_{i} X_{i, w}^{f} \leq R_{w} \quad \forall w \in W
$$

$R_{w}$ is the capacity of biorefinery $w$.

All the biofuel produced at each biorefinery from each type of feedstock is shipped to all demand zones.

$$
\sum_{n} Q_{i, w, n}^{f}=X_{i, w}^{f} \quad \forall i \in I, w \in W
$$

$Q_{i, w, n}^{f}$ is the amount of biofuel, which is produced from feedstock type $i$, shipped from biorefinery $w$ to demand zone $n$.

The total quantity of biofuel shipped from all biorefineries to each demand zone, should fulfil the demand.

$$
\sum_{i} \sum_{w} Q_{i, w, n}^{f} \geq D_{n} \quad \forall n \in N
$$

$D_{n}$ represents the demand at each demand zone. 
It should be noted that all the variables are non-negative. It can be summarised that

$$
\min \quad F=\left(C^{\text {Total }}, E^{\text {Total }}, Q_{e}^{\text {Total }}\right)
$$

subject to constraints

where $C^{\text {Total }}, E^{\text {Total }}, Q_{e}^{\text {Total }}$ and contraints are discussed above.

\section{Case study}

The case study is assessed for Malaysian biofuel supply chain management. Malaysia are located in east Asia which has 13 states and three federal territories. 11 states and two federal territories are located in Peninsular Malaysia, and two states are located in East Malaysia. We assumed that federal territories, Putrajaya and Labuan has no biomass resource. The resources in state of Perlis are assumed to be located in state of Kedah. Each state has preprocessing plant, which is located nearby resource location. Transportation from resources to biodiesel plant will be performed by land and sea. Biodiesel plants are located in several states such as Sabah, Johor, Selangor, Pahang, Perak and Negeri Sembilan. Biofuel from the biodiesel plants are transported by land and sea transportation to demand zone. The structure of biodiesel supply chain is as shown in Figure 1.

The MOLP model introduced in the previous section is used to consider the economic, environmental and social performances of biodiesel production from oil palm fruit and jatropha in Malaysia. In this study $\epsilon$-constraint method is used for solving the optimisation problem.

Biodiesel, as a product of the chemical reaction of oil or fat with an alcohol, has received considerable attention due to the resulting similarities of the biofuel produced with petroleum diesel. Malaysia produces large volumes of biodiesel (Johanston and Hollaway, 2007). Various kinds of feedstock can be used as sources for biodiesel production. Over $95 \%$ of biodiesel is currently produced from edible oil (Yusuf et al., 2011). Malaysia is an equatorial country with an average rainfall of $250 \mathrm{~cm}$ a year and daily temperatures that fluctuate between $20^{\circ} \mathrm{C}$ and $30^{\circ} \mathrm{C}$ (Swee-Hock, 2007). The country has two geographically distinct components, Peninsular Malaysia in the west and East Malaysia in the east. A detailed description of the case study follows.

\subsection{Feedstock resource}

In this study, each state is considered as a feedstock resource. As the resources are spread across the states, to calculate the transport distances, resources are assumed to be lumped at the centre of each state.

\subsection{Feedstock data}

The annual fresh fruit bunch (FFB) yield in each state in 2012 (average yields reported for three years up to 2012) and the total area covered by mature oil palm plantations in Malaysia were obtained from the Malaysian Palm Oil Board (MPOB), which are shown 
in Tables 4 and 5. The average yield of crude palm oil in 2012 was $20.35 \%$ by weight (Malaysian Palm Oil Board, 2013). Production and harvesting cost of FFB provided by Wahid and Simeh (2009) is MYR 214/t FFB. Production cost of FFB consists of up-keeping, fertiliser application, harvesting, in-field transportation and general charges. The extraction cost of crude palm oil from FFB is estimated at MYR 36.25/t FFB by Man and Baharum (2011) for large scale palm oil mills.

Table 4 Annual yield of FFB

\begin{tabular}{lc}
\hline State & Yield $($ t/ha $)$ \\
\hline Johor & 19.02 \\
Kedah* & 21.43 \\
Kelantan & 11.89 \\
Melaka & 23.30 \\
N. Sembilan & 19.88 \\
Pahang & 18.94 \\
Penang & 16.88 \\
Perak & 21.35 \\
Selangor & 20.91 \\
Terengganu & 15.35 \\
Sabah & 20.40 \\
Sarawak & 16.51 \\
\hline
\end{tabular}

Note: * State Perlis is assumed to include in Kedah.

Table 5 Area under mature oil palm plantation

\begin{tabular}{lc}
\hline State & Oil palm planted area $($ ha $)$ \\
\hline Johor & 618,353 \\
Kedah & 76,181 \\
Kelantan & 91,182 \\
Melaka & 48,718 \\
N. Sembilan & 143,580 \\
Pahang & 595,799 \\
Penang & 13,264 \\
Perak & 338,100 \\
Selangor & 124,080 \\
Terengganu & 136,509 \\
Sabah & $1,292,757$ \\
Sarawak & 874,152 \\
\hline
\end{tabular}

Malaysia has good climate conditions for the cultivation of jatropha. The potential area for the cultivation of jatropha is given in Table 6 (Jatropha Curcas Grower Murabahah Programme, 2012). Since jatropha grows in all types of soils and even marginal lands (Gour, 2006; Ong et al., 2011); it has been assumed that the total area under jatropha plantation in each state is proportional to the state's area. According to the Bionas jatropha biodiesel project, the yield per acre is 3.6 metric tons of fruits in the first three years. Jatropha oil is obtained from jatropha seeds. The oil content of jatropha seed 
is around 33\% (About Jatropha Curcas, 2013). The production cost of jatropha was estimated at MYR 535/t seed based on Puteh and Sivapragasam's (2008) presentation. The crushing cost of jatropha seeds has been reported at MYR 170/t seed (Global NRG Ltd., 2013).

Table 6 Potential area for cultivation of jatropha

\begin{tabular}{lc}
\hline Region & Area \\
\hline Peninsular Malion acres) \\
Sabah & 8.5 \\
Sarawak & 10.4 \\
\hline
\end{tabular}

It should be noted that an appropriate producer price index (PPI), which includes the inflation rate, was used to inflate the costs. Furthermore, all costs are converted to Malaysian Ringgit with the exchange rate of 3.03.

\subsection{Biorefinery location}

According to MPOB and the American Palm Oil Council (APOC) presentation in 2010, 12 biodiesel plants have been in operation and four plants have completed construction in Malaysia. These plants are located in six states. Each state is considered as a biorefinery location. It has been presumed that the biorefineries are located at the centre of each state and that each biorefinery handles jatropha oil as well as palm oil. These plants are located in Sabah, Johor, Selangor, Pahang, Perak and Negeri Sembilan.

\subsection{Transportation}

It is assumed that transportation in West Malaysia is performed by diesel truck and transportation between the east and west is performed by ship. All the items in the West that are to be transported to East Malaysia, are transferred to Port Klang and shipped to Kota Kinabalu in Sabah and Kuching in Sarawak. The distance between each pair of states and ports was obtained from Google Maps and the Ports website (Sea Routs and Distance, 2012). The cost of transportation by truck is based on data reported by Kim et al. (2011). The ocean freights were obtained from Malaysia Logistics Buzz (Sea Routs and Distance, 2013). Similar to the feedstock related costs, the costs of transportation via truck are inflated using an appropriate PPI.

\subsection{Biodiesel production}

Biodiesel is produced using different methods. The most common method for biodiesel production is transesterification (Barnawal and Sharma, 2005). The chemical conversion of vegetable oil or fats to biodiesel is called transesterification (Demirbas, 2007). According to the study by Singh et al. (2006), the optimal yield of biodiesel using an alkaline catalyst, which is normally used for biodiesel production, is $95.8 \%$. 


\subsection{Demand data}

According to data obtained from the Malaysia Energy Information Hub (MEIH), the final demand for biodiesel in Malaysia in 2012 was 115 ktoe. In this study, each state is considered as a demand zone and it has been assumed that the demand of each state is proportional to its population.

\subsection{Emission factors}

The emissions data were carried out from the method specified by the UK renewable fuel agency (UK Renewable Fuels Agency, 2010). The total GHG emissions resulting from a biodiesel supply chain is reported in terms of $\mathrm{CO}_{2}$ equivalent. The emission factors for palm oil and jatropha are summarised in Tables 7 and 8 .

Table 7 Palm oil production, transportation and conversion emission factor

\begin{tabular}{lc}
\hline Stage of supply chain & Emission \\
\hline Crop production & $81.34\left(\mathrm{~kg} \mathrm{CO}_{2} / \mathrm{t} \cdot \mathrm{FFB}\right)$ \\
Feedstock pre-processing & $516.6\left(\mathrm{~kg} \mathrm{CO}_{2} / \mathrm{t} \cdot \mathrm{CPO}\right)$ \\
Feedstock transportation (road) & $0.15\left(\mathrm{~kg} \mathrm{CO}_{2} / \mathrm{t} \cdot \mathrm{km}\right)$ \\
Feedstock transportation (ship) & $0.02\left(\mathrm{~kg} \mathrm{CO}_{2} / \mathrm{t} \cdot \mathrm{km}\right)$ \\
Conversion & $580\left(\mathrm{~kg} \mathrm{CO}_{2} / \mathrm{t} \cdot \mathrm{biodiesel}\right)$ \\
Biofuel transportation (road) & $0.15\left(\mathrm{~kg} \mathrm{CO}_{2} / \mathrm{t} \cdot \mathrm{km}\right)$ \\
Biofuel transportation (ship) & $0.02\left(\mathrm{~kg} \mathrm{CO}_{2} / \mathrm{t} \cdot \mathrm{km}\right)$ \\
\hline
\end{tabular}

Table 8 Jatropha production, transportation and conversion emission factor

\begin{tabular}{lc}
\hline Stage of supply chain & Emission \\
\hline Crop production & $42.78\left(\mathrm{~kg} \mathrm{CO}_{2} / \mathrm{t} \cdot \mathrm{seed}\right)$ \\
Feedstock pre-processing & $43.24\left(\mathrm{~kg} \mathrm{CO}_{2} / \mathrm{t} \cdot \mathrm{jatropha}\right.$ oil $)$ \\
Feedstock transportation (road) & $0.15\left(\mathrm{~kg} \mathrm{CO}_{2} / \mathrm{t} \cdot \mathrm{km}\right)$ \\
Feedstock transportation (ship) & $0.02\left(\mathrm{~kg} \mathrm{CO}_{2} / \mathrm{t} \cdot \mathrm{km}\right)$ \\
Conversion & $471\left(\mathrm{~kg} \mathrm{CO}_{2} / \mathrm{t} \cdot \mathrm{biodiesel}\right)$ \\
Biofuel transportation (road) & $0.15\left(\mathrm{~kg} \mathrm{CO}_{2} / \mathrm{t} \cdot \mathrm{km}\right)$ \\
Biofuel transportation (ship) & $0.02\left(\mathrm{~kg} \mathrm{CO}_{2} / \mathrm{t} \cdot \mathrm{km}\right)$ \\
\hline
\end{tabular}

\section{Solution strategy}

The $\varepsilon$-constraint method is one of the most widely used methods for multi-objective optimisation problems in finding the most optimal solutions (Mavrotas, 2009). This method is based on the aggregation of multi-objective optimisation problems into single-objective problems. The steps of $\varepsilon$-constraint method are as follows (Diwekar, 2008): 
1 One of the objectives is chosen as the main objective function.

2 The upper bound of parameter $\varepsilon$ is determined by solving the optimisation problem for the main objective which is chosen in the first step.

3 The problem is solved according to each sub-objective function, separately. The optimal solutions obtained by optimisation, represent the lower bound of parameter $\varepsilon$.

4 The Pareto optimal set is defined by running the model with the main objective function and different values of $\varepsilon$ which are laid between the lower and upper bounds of $\varepsilon$.

\section{Result and discussion}

The MOLP model presented in this study has been solved with the $\varepsilon$-constraint method. The model was coded in MATLAB software and was solved using a linear programming solver.

In this study, the economic objective is considered as the main objective and the environmental and social criteria are transformed into constraints. The determination of the lower and upper bounds of $\varepsilon$ for each objective function is the next step in this method. The lower bound of $\varepsilon$ is determined by minimising the environmental and social objectives subject to constraints, separately. In the last step, $\varepsilon$ is fixed to 10 intervals between the lower and upper bounds for each sub-objective and added as a constraint to the model. In this way, one optimal solution is obtained in each run. An approximation of Pareto optimal set is defined by running the model for different values of $\varepsilon$. The proposed MOLP model and solution strategy were applied to the case study in Malaysia.

Table 9 demonstrates the trade-offs among the economic, environmental and social objectives, which are obtained through the optimisation process, for the selected case study. In this table, each row represents an optimal solution for planning of biodiesel supply chain.

Table 9 Optimal solutions

\begin{tabular}{lccc}
\hline Solution & $\begin{array}{c}\text { Total annual cost } \\
(\text { MYR })\end{array}$ & $\begin{array}{c}\text { GHG emissions } \\
(t \text { CO }\end{array}$ & $\begin{array}{c}\text { Edible feedstock consumption } \\
(t)\end{array}$ \\
\hline $\mathrm{S}_{1}$ & $384,460,000$ & 99,017 & 64,972 \\
$\mathrm{~S}_{2}$ & $368,840,000$ & 106,760 & 131,110 \\
$\mathrm{~S}_{3}$ & $355,410,000$ & 117,510 & 203,240 \\
$\mathrm{~S}_{4}$ & $341,550,000$ & 123,260 & 251,240 \\
$\mathrm{~S}_{5}$ & $326,990,000$ & 146,000 & 340,440 \\
$\mathrm{~S}_{6}$ & $311,850,000$ & 157,750 & 410,632 \\
$\mathrm{~S}_{7}$ & $298,120,000$ & 167,500 & 459,771 \\
$\mathrm{~S}_{8}$ & $282,810,000$ & 187,250 & 521,892 \\
$\mathrm{~S}_{9}$ & $268,290,000$ & 196,990 & 607,030 \\
$\mathrm{~S}_{10}$ & $254,510,000$ & 204,630 & 685,420 \\
\hline
\end{tabular}


Comparing the optimal solutions reveals that decreasing the operational cost causes an increase in edible feedstock consumption and GHG emissions. The decision maker can take the one from a set of solutions that fits the requirements. In this case, solution $\mathrm{S}_{5}$ has been selected as a good choice among optimal solutions, because the total GHG emissions and edible feedstock consumption decreased significantly at this point, while the operational cost is approximately in the middle of its lowest and highest acceptable amounts. From another point of view, based on the Malaysian Biodiesel Association's calculations in 2007, palm oil biodiesel could be produced for MYR 2,960/t when the price of CPO is at MYR 2,500/t and the operating cost is taken into account, whereas the cost of biodiesel production at biorefineries for the selected optimal solution is MYR 2,575/t biodiesel.

Tables 10 and 11 show the summary of decisions related to solution $\mathrm{S}_{5}$.

Table 10 Optimisation results for harvesting and pre-processing of biomass

\begin{tabular}{lcc}
\hline $\begin{array}{c}\text { Type of } \\
\text { biomass }\end{array}$ & $\begin{array}{c}\text { Quantity of biomass } \\
\text { to be harvested (t/year) }\end{array}$ & $\begin{array}{c}\text { Quantity of pre-processed feedstock } \\
\text { shipped to biorefineries (t/year) }\end{array}$ \\
\hline Palm oil fruit & 340,440 & 68,090 \\
Jatropha & 210,190 & 69,366 \\
\hline
\end{tabular}

Table 11 Optimisation results for production and distribution of biodiesel

\begin{tabular}{lcc}
\hline Biofuel & $\begin{array}{c}\text { Quantity of biofuel } \\
\text { produced (t/year) }\end{array}$ & $\begin{array}{c}\text { Quantity of biofuel shipped } \\
\text { to demand zones (t/year) }\end{array}$ \\
\hline Palm oil biodiesel & 61,960 & 61,960 \\
Jatropha biodiesel & 63,121 & 63,121 \\
\hline
\end{tabular}

\section{Conclusions}

A mathematical model for optimal planing of biofuel supply chain considering production line, environmental and social factors is developed. Developed model is followed the MOLP standard form. A MOLP model was proposed to minimise the total operational cost, GHG emissions and edible feedstock consumption used in the production of biofuel. The proposed model was illustrated through the case study for production of biodiesel from palm oil and jatropha in Malaysia. The model was solved using the $\varepsilon$-constraint method.

The results showed that production of biodiesel in Malaysia from a combination of palm oil and jatropha is most sustainable. According to the optimal solutions obtained from the optimisation process, reducing the operational cost causes an increase in GHG emissions and edible feedstock consumption. The selected optimal solution at MYR $326,990,000$ operational cost, 146,000 t $\mathrm{CO}_{2}$ emissions and 340,440 t edible feedstock consumption, could be a good solution for the production of biodiesel in Malaysia, as the total emissions and edible feedstock consumption are significantly decreased. 


\section{References}

About Jatropha Curcas (2013) http://www.bionas.com.my/jatrophacurcas.html (accessed April 2013).

An, H., Wilhelm, W.E. and Searcy, S.W. (2011) 'A mathematical model to design a lignocellulosic biofuel supply chain system with a case study based on a region in Central Texas', Bioresource Technol., Vol. 102, No. 17, pp.7860-7870.

Barnawal, B.K. and Sharma, M.P. (2005) 'Prospects of biodiesel production from vegetable oils in India', Renew. Sust. Energ. Rev., Vol. 9, No. 4, pp.363-378.

Bottani, E., Montanari, R., Rinaldi, M. and Vignali, G. (2015) 'Modeling and multi-objective optimization of closed loop supply chains: a case study', Computers Industrial Engineering, Vol. 87, pp.328-342.

Corsano, G., Vecchietti, A.R. and Montagna, J.M. (2011) 'Optimal design for sustainable bioethanol supply chain considering detailed plant performance model', Comput. Chem. Eng., Vol. 35, pp.1384-1398.

Demirbas, A. (2007) 'Importance of biodiesel as transportation fuel', Energy Policy, Vol. 35, No. 9 , pp.4661-4670.

Diwekar, U. (2008) Introduction to Applied Optimization, 2nd ed., Springer, USA.

Drapcho, C.M., Nhuan, N.P. and Walker, T.H. (2008) Biofuels Engineering Process Technology, McGraw-Hill, New York.

Dunnett, A., Adjiman, C. and Shah, N. (2007) 'Biomass to heat supply chains: applications of process optimization', Process Saf. Environ., Vol. 85, No. 5, pp.419-429.

Eksioğlu, S.D., Acharya, A., Leightley, L.E. and Arora, S. (2009) 'Analyzing the design and management of biomass-to-biorefinery supply chain', Comput. Ind. Eng., Vol. 57, No. 4, pp.1342-1352.

FAO (2008) 'Soaring food prices: facts, perspectives, impacts and actions required', Paper presented at the High-level Conference on World Food Security: The Challenges of Climate Change and Bioenergy, Rome, June.

Giarola, S., Zamboni, A. and Bezzo, F. (2011) 'Spatially explicit multi-objective optimisation for design and planning of hybrid first and second generation biorefineries', Comput. Chem. Eng., Vol. 35, No. 9, pp.1782-1797.

Global NRG Ltd. (2013) 'Facts and figures on Jatropha' [online] http://www.nuglobalnrg.com/ (accessed October 2013).

Matthieu Godichaud and Lionel Amodeo, () 'Efficient multi-objective optimization of supply chain with returned products', Journal of Manufacturing Systems, Part 3, Vol. 37, pp.683-691, Reverse Supply Chains.

Gour, V.K. (2006) 'Production practices including post harvest management of jatropha curcas', Biodiesel Conference Towards Energy Independence - Focus on Jatropha, Rashtrapati Nilayam, Hyderabad, 9-10 June.

Gunnarsson, H., Ronnqvist, M. and Lundgren, J.T. (2004) 'Supply chain modelling of forest fuel', Eur. J. Oper. Res., Vol. 158, No. 1, pp.103-123.

Holditch, S.A. and Chianelli, R.R. (2008) 'Factors that will influence oil and gas supply and demand in the 21st century', MRS Bulletin, Vol. 33, pp.317-323.

Huang, Y., Chen, C.H. and Fan, Y. (2010) 'Multistage optimization of the supply chains of biofuels', Transportation Research Part E: Logistics and Transportation Review, Vol. 46, No. 6, pp.820-830.

Jatropha Curcas Grower Murabahah Programme (2012) [online] http://www.murabahah.biofuelbionas.com/development.html (accessed March 2012). 
Johanston, M. and Hollaway, T. (2007) 'A global comparison of national biodiesel production potentials', Environ. Sci. Technol., Vol. 41, No. 23, pp.7967-773.

Kim, J., Realff, M.J., Lee, J.H., Whittaker, C. and Furtner, L. (2011) 'Design of biomass processing network for biofuel production using an MILP model', Biomass Bioenerg, Vol. 35, No. 2, pp.853-871.

Liu, S. and Papageorgiou, L.G. (2013) 'Multiobjective optimisation of production, distribution and capacity planning of global supply chains in the process industry', Omega, Vol. 41, No. 2, pp.369-382, Management Science and Environmental issues.

Malaysian Palm Oil Board (2013) [online] http://mpob.gov.my (accessed February 2013).

Man, E.L.Y. and Baharum, A. (2011) 'A qualitative approach of identifying major cost influencing factors in palm oil mills and the relations towards production cost of crude palm oil', Am. J. Appl. Sci., Vol. 8, No. 5, pp.441-446.

Marvin, W.A., Schmidt, L.D. and Daoutidis, P. (2013) 'Biorefinery location and technology selection through supply chain optimization', Industrial \& Engineering Chemistry Research, Vol. 52, No. 9, pp.3192-3208.

Mavrotas, G. (2009) 'Effective implementation of the $\epsilon$-constraint method in multi-objective mathematical programming problems', Appl. Math. Comput., Vol. 213, No. 2, pp.455-465.

Mele, F.D., Guillén-Gosalbez, G. and Jiménez, L. (2009) 'Optimal planning of supply chains for bioethanol and sugar production with economic and environmental concerns', Comput. Aided Chem. Eng., Vol. 26, pp.997-1002.

National Petroleum Council (2007) Hard Truths: Facing the Hard Truths about Energy: A Comprehensive View to 2030 of Global Oil and Natural Gas, Washington DC.

Niknamfar, A.H. (2015) 'Multi-objective production-distribution planning based on vendor-managed inventory strategy in a supply chain', Industrial Management \& Data Systems, Vol. 115, No. 6, pp.1086-1112.

Ong, H.C., Mahlia, T.M.I., Masjuki, H.H. and Norhasyima, R.S. (2011) 'Comparison of palm oil, jatropha curcas and calophyllum inophyllum for biodiesel: a review', Renewable and Sustainable Energy Reviews, Vol. 15, No. 8, pp.3501-3515.

Parker, N., Fan, Y. and Ogden, J. (2010) 'From waste to hydrogen: an optimal design of energy production and distribution network', Transportation Research Part E: Logistics and Transportation Review, Vol. 46, No. 4, pp.534-545.

Popp, J., Lakner, Z., Harangi-Rákos, M. and Fári, M. (2014) 'The effect of bioenergy expansion: food, energy, and environment', Renewable and Sustainable Energy Reviews, Vol. 32, pp.559-578, doi: 10.1016/j.rser.2014.01.056.

Puteh, M. and Sivapragasam, A. (2008) Jatropha Curcas: Economical and Technical Perspectives as a Smallholder Crop in Malaysia, Malaysian Agricultural Research and Development (MARDI).

Rosegrant, M.W., Msangi, S., Sulser, T. and Valmonte-Santos, R. (2006) 'Bioenergy and agriculture: promises and challenges,biofuels and the global food balance', Bioenergy and Agricultural: Promises and Challenges, Vol. 14, No. 3.

Santibanez-Aguilar, J.E., Gonzalez-Campos, J.B., Ponce-Ortega, J.M., Serna-Gonzalez, M. and El-Halwagi, M.M. (2011) 'Optimal planning of a biomass conversion system considering economic and environmental aspects', Ind. Eng. Chem. Res., March, Vol. 50, No. 14, pp.8558-8570.

Sea Routs and Distance, (2012) [online] http://www.ports.com/sea-route/ (accessed May 2012).

Malaysia Logistic Buzz (2013) 'Ocean freight as of FEB 2013 (domestics) West to East Malaysia’ [online] http://malaysialogisticsbuzz.blogspot.com/2012/01/ ocean-freight-as-of-jan-20\%12-domestics.html (accessed March 2013). 
Singh, A., He, B., Thompson, J. and Van Gerpen, J. (2006) 'Process optimization of biofuel production using alkaline catalysts', Appl. Eng. Agric., Vol. 22, No. 4, pp.597-600.

Swee-Hock, S. (2007) The Population of Peninsular Malaysia, 2nd ed., Institute of Southeast Asian Studies, Singapore.

Timilsina, G.R. and Shrestha, A. (2011) 'How much hope should we have for biofuels?', Energy, Vol. 36, No. 4, pp.2055-2069.

UK Renewable Fuels Agency (2010) Carbon and Sustainability Reporting within the Renewable Transport Fuel Obligation, Technical Guidance Part Two Carbon Reporting - Default Values and Fuel Chains, Renewable Fuel Agency, UK.

Wahid, M.B. and Simeh, M.A. (2009) 'Issues related to production cost of palm oil in Malaysia', Oil Palm Industry Economic J., Vol. 9, No. 2, pp.1-12.

Yang, Z., Cai, X. and Fan, Z. (2014) 'Epsilon constrained method for constrained multiobjective optimization problems: Some preliminary results', in Proceedings of the Conference Companion on Genetic and Evolutionary Computation Companion, GECCO Comp, pp.1181-1186, ACM, New York, NY, USA.

You, F. and Wang, B. (2011) 'Life cycle optimization of biomass-to-liquid supply chains with distributed-centralized processing networks', Ind. Eng. Chem. Res., Vol. 50, pp.10102-10127.

You, F., Tao, L., Graziano, D.J. and Snyder, S.W. (2012) 'Optimal design of sustainable cellulosic biofuel supply chains: multiobjective optimization coupled with life cycle assessment and input-output analysis', AIChE Journal, Vol. 58, No. 4, pp.1157-1180.

Yusuf, N.N.A.N., Kamarudin, S.K. and Yaakub, Z. (2011) 'Overview on the current trends in biodiesel production', Energ. Convers. Manage., Vol. 52, No. 7, pp.2741-2751.

Zarrilli, S. (2006) 'The emerging biofuels market: Regulatory, trade and development implications', Paper presented at the United Nations Conference on Trade and Development, New York and Geneva. 